\title{
Combined ultrasound-guided Pecs II block and general anesthesia are effective for reducing pain from modified radical mastectomy
}

This article was published in the following Dove Press journal:

Journal of Pain Research

Tjokorda Gde Agung Senapathi

I Made Gede Widnyana

I Gusti Ngurah Mahaalit

Aribawa

A A Gde Putra Semara Jaya

I Made Darma Junaedi

Department of Anesthesiology and Intensive Care, Sanglah Hospital, Faculty of Medicine, Udayana University,

Denpasar, Bali, Indonesia
Correspondence: A A Gde Putra

Semara Jaya

Department of Anesthesiology and

Intensive Care, Sanglah Hospital, Faculty

of Medicine, Udayana University,

Diponegoro Street, Denpasar, Bali

80114 , Indonesia

Tel +628 I9I 6241248

Fax $+6236 \quad 1235980$

Email gungthey84@yahoo.com
Purpose: Combined regional and general anesthesia are often used for the management of breast cancer surgery. Thoracic spinal block, thoracic epidural block, thoracic paravertebral block, and multiple intercostal nerve blocks are the regional anesthesia techniques which have been used in breast surgery, but some anesthesiologists are not comfortable because of the complication and side effects. In 2012, Blanco et al introduced pectoralis nerve (Pecs) II block or modified Pecs block as a novel approach to breast surgery. This study aims to determine the effectiveness of combined ultrasound-guided Pecs II block and general anesthesia for reducing intra- and postoperative pain from modified radical mastectomy.

Patients and methods: Fifty patients undergoing modified radical mastectomy with general anesthesia were divided into two groups randomly $(n=25)$, to either Pecs $(P)$ group or control (C) group. Ultrasound-guided Pecs II block was done with $0.25 \%$ bupivacaine ( $\mathrm{P}$ group) or $0.9 \% \mathrm{NaCl}$ (C group). Patient-controlled analgesia was used to control postoperative pain. Intraoperative opioid consumption, postoperative visual analog scale (VAS) score, and postoperative opioid consumption were measured.

Results: Intraoperative opioid consumption was significantly lower in $\mathrm{P}$ group $(P \leq 0.05)$. VAS score at $3,6,12$, and 24 hrs postoperative were significantly lower in $\mathrm{P}$ group $(P \leq 0.05)$. Twenty-four hours postoperative opioid consumption was significantly lower in $\mathrm{P}$ group $(P \leq 0.05)$. There are no complications following Pecs block in both groups, including pneumothorax, vascular puncture, and hematoma.

Conclusion: Combined ultrasound-guided Pecs II block and general anesthesia are effective in reducing pain both intra- and postoperatively in patients undergoing modified radical mastectomy. Ultrasound-guided Pecs II block is a relatively safe peripheral nerve block.

Keywords: Pecs block, interfascial injection, regional anesthesia, ultrasound-guided, pain, modified radical mastectomy, breast surgery

\section{Introduction}

The effective acute postoperative pain management of breast surgery is necessary. Uncontrolled acute postoperative pain is one of the risk factors for chronic pain. Turan et $\mathrm{al}^{1}$ study reported that chronic pain was detected in $41.8 \%$ of the patients who had severe acute postoperative pain. Combined regional and general anesthesia are the common management for breast cancer surgery. Regional anesthesia provides anesthesia/analgesia during and after surgery. A regional technique continued into the postoperative period offers postoperative analgesia, attenuation of the surgical stress response, reduction in postoperative nausea and vomiting (PONV), 
and early mobilization. Thoracic spinal block (TSB), thoracic epidural block, thoracic paravertebral block (TPVB), and multiple intercostal nerve blocks are the regional anesthesia techniques which have been used in breast surgery. Those techniques have disadvantages including pneumothorax (1\% TPVB, $2 \%$ intercostal), bleeding risk (especially epidural hematoma), dural puncture, and hypotension. ${ }^{2,3}$ In 2011, Blanco ${ }^{4}$ presented a novel interfascial plane block between the pectoralis major and minor muscles called Pecs block, which later became known as Pecs I block. In 2012, Blanco et $\mathrm{al}^{5}$ introduced Pecs II block or modified Pecs block as a novel approach to breast surgery. Pecs block are newer US-guided blocks with low risk of complication. ${ }^{6-8}$

Several randomized controlled trials (RCT) regarding Pecs II block have been done. The effectiveness of Pecs II block for breast surgery has been compared with TPVB by Wahba et al and Kulhari et al, and with TSB by ELdeen. Wahba et $\mathrm{al}^{9}$ and Kulhari et $\mathrm{al}^{10}$ concluded that Pecs II block reduces postoperative opioid consumption and provides better pain relief compared with the TPVB. ELdeen ${ }^{11}$ concluded that Pecs II block and TSB provide effective intraoperative anesthesia and postoperative pain relief, but the Pecs II block is simpler and safer. Other RCTs, ie, Bashandy et $\mathrm{al}^{12}$, El-Sheikh et $\mathrm{al}^{13}$, and Kim et $\mathrm{al}^{14}$, compared the effectiveness of combined Pecs II block and general anesthesia versus general anesthesia alone for breast surgery. Those studies concluded that Pecs block reduced pain intensity and opioid requirements when combined with general anesthesia for breast surgery. However, those studies were not double-blind and placebo-controlled.

This double-blind RCT tried to determine the effectiveness of combined Pecs II block and general anesthesia for reducing intra- and postoperative pain from modified radical mastectomy.

\section{Patients and methods}

\section{Patients}

This is an experimental study with a double-blind, randomized, placebo-controlled trial design. This study involved 50 patients with physical status American Society of Anesthesiologist (ASA) I-II, aged 16-65 years old, undergoing unilateral modified radical mastectomy with general anesthesia in the central operating theater at Sanglah Hospital (Joint Commission International - Accredited) from May through July 2018. The patient was not admitted to the study if any the following criteria were present: patient refusal, physical status ASA III or more, contraindications using local anesthetics, local infection at the site of injection, and a history of chronic analgesic use.

Subjects were randomly divided into two groups, to either Pecs (P) group or control (C) group using permuted block randomization by a research assistant with no clinical involvement in the study. The drugs were prepared by independent pharmacist and placed into envelopes according to the allocation orders. Both drugs cannot be distinguished because they contain the same colored liquid and the same volume. The detailed information was concealed in an envelope and revealed to the researchers after the study was over. The subject will be dropped out when such condition occurs: surgical duration $>6 \mathrm{hrs}$, local anesthetic systemic toxicity, and discharge against medical advice before 24 hrs postoperatively. There was no loss of subject in this study.

\section{Procedures}

In the preparation room of central operating theater, intravenous (IV) access was obtained, crystalloid solutions and midazolam $0.03 \mathrm{mg} / \mathrm{kg}$ were administered intravenously. In the operating room, standard ASA monitors were placed and general anesthesia was done using IV propofol $2-2.5 \mathrm{mg} / \mathrm{kg}$ and fentanyl $2 \mathrm{mcg} / \mathrm{kg}$ as induction agents. Tracheal intubation facilitated by $0.5 \mathrm{mg} / \mathrm{kg}$ IV atracurium. General anesthesia was maintained with sevoflurane and $60 \%$ oxygen mixed with compressed air. The concentration of sevoflurane was adjusted to maintain a bispectral index between 40 and 60 . Intravenous fentanyl $1 \mathrm{mcg} / \mathrm{kg}$ was administered if variations in systolic blood pressure and heart rate of $\geq 20 \%$ basal values.

Following induction of general anesthesia, ultrasoundguided Pecs II block was performed under complete aseptic technique using high frequency $(15-6 \mathrm{MHz})$ linear array probe of SonoSite M-Turbo ${ }^{\circledR}$ ultrasound (US) system (FUJIFILM SonoSite, Bothell, WA, USA) by regional anesthesiologist staff who was blinded to the randomized intervention. The technique used was in accordance with the description by Blanco and Barrington. ${ }^{15}$ Patient in the supine position, with the arm abducted 90 degrees. The probe was placed below the clavicle, locates the coracoid process on US in the paramedian sagittal plane. The transducer was rotated slightly to allow an in-plane needle trajectory from the proximal and medial side toward the lateral side. A first injection was made between the pectoral major and minor muscles. The transducer was then moved laterally, and a second injection was made between the pectoralis minor and serratus anterior muscles. ${ }^{15}$ The 
block was performed by using a 22-gauge, $100 \mathrm{~mm}$ needle Stimuplex ${ }^{\circledR}$ Ultra (B. Braun Medical Inc., Pennsylvania, USA). Either $0.25 \%$ bupivacaine (P group) or $0.9 \% \mathrm{NaCl}$ (C group) was administered, with volume $10 \mathrm{~mL}$ for the first injection and $20 \mathrm{~mL}$ for the second injection.

Postoperatively, patients received IV PCA morphine and IV bolus of ketorolac $30 \mathrm{mg}$ every $8 \mathrm{hrs}$ as analgesia. The CADD-Legacy® PCA Pump (Smiths Medical International Ltd, Kent, UK) was loaded with $1 \mathrm{mg} / \mathrm{mL}$ of morphine and set to administer an on-demand dose of $1 \mathrm{~mL}, 6$ mins lockout interval, a maximum dose of $3 \mathrm{mg}$ per hour, and no continuous infusion. Intraoperative opioid consumption, postoperative VAS score, and postoperative opioid consumption were measured.

\section{Statistical analyses}

All statistical analyses were performed using IBM SPSS for Windows (IBM Corporation, Armonk, NY, USA) software version 20. Numerical variable expressed as mean $\pm \mathrm{SD}$ or median (IQR). Categorical variable expressed as frequency $(\%)$. Test of normality using Shapiro-Wilk test and homogeneity test using Levene's test. Compare mean test using independent-sample $t$-test if data distribution were normal or using nonparametric test Mann-Whitney $U$ if not distributed normally. Chi-square test was used for a categorical variable. The level of significance $\alpha 0.05$.

The required sample size was calculated using compare two means formula. Taking the intraoperative fentanyl consumption with a standard deviation of $37.3 \mathrm{mcg}$ from previous study, ${ }^{12}$ for clinically important difference of $25 \mathrm{mcg}$, at a significance level ( $\alpha$ ) $5 \%$, power (1- $\beta$ ) $90 \%$, and a drop-out rate of $10 \%$, then 50 patients $(25$ patients per group) should be sufficient.

\section{Ethics statement}

Ethical clearance of this study has been approved by the Research Ethics Committee of Faculty of Medicine Udayana University and Sanglah Hospital and in accordance with the Declaration of Helsinki. Prior to participation, all involved subjects and subject's parents or legal guardians (for participants under the age of 18 years) gave written informed consent and were fully informed of the procedures in the studies.

\section{Results}

There were no significant differences $(P>0.05)$ in both groups in terms of age, body mass index, ASA physical status, and duration of surgery (Table 1). The mean of age
Table I Subject characteristics

\begin{tabular}{|l|l|l|l|}
\hline \multirow{2}{*}{ Characteristics } & \multicolumn{2}{|l|}{ Groups } & \multirow{2}{*}{ P-value } \\
\cline { 2 - 3 } & P (n=25) & C (n=25) & \\
\hline Age (years) & $47.7 \pm 7.4$ & $45.9 \pm 11.4$ & $0.510^{\mathrm{a}}$ \\
BMI (kg/m $\left.\mathrm{m}^{2}\right)$ & $22.8(3.2)$ & $23.8(2.9)$ & $0.409^{\mathrm{b}}$ \\
ASA physical status & $7(28 \%)$ & $9(36 \%)$ & $0.544^{\mathrm{c}}$ \\
ASA I & $18(72 \%)$ & $16(64 \%)$ & \\
ASA II & & & \\
Duration of surgery (mins) & $110(18)$ & $100(23)$ & $\left.0.89\right|^{\mathrm{b}}$ \\
\hline
\end{tabular}

Notes: Values are expressed as mean \pm SD or median (IQR) for numerical data and frequency (\%) for categorical data, ${ }^{a}$ Independent $t$-test, ${ }^{b}$ Mann Whitney $\mathrm{U}$ test, ${ }^{\mathrm{c}} \mathrm{Chi}-$ square test.

Abbreviations: ASA, American Society of Anesthesiologist; BMI, body mass index; C, control group; $n$, number of subjects; P, Pecs group.

(years) in P group was $47.7 \pm 7.4$ and $45.9 \pm 11.4$ in $\mathrm{C}$ group. The median duration of surgery was 110 (18) mins in $\mathrm{P}$ group and 100 (23) mins in $\mathrm{C}$ group.

As given in Table 2, the intraoperative opioid consumption (fentanyl) was significantly different $(P \leq 0.05)$. Patients in $\mathrm{C}$ group need more intraoperative fentanyl than patients in P group (median of 250 (75) mcg and 125 (25) mcg, respectively), with $P$-value $<0.001$.

Postoperative VAS scores were significantly different at all times of evaluation $(P \leq 0.05)$. As shown in Table 3 and Figure 1, postoperative VAS scores were higher in $\mathrm{C}$ group than P group at 3, 6, 12, and $24 \mathrm{hrs}$ after surgery. The peak of the mean of postoperative pain score was at $3 \mathrm{hrs}$ in $\mathrm{C}$ group and at $12 \mathrm{hrs}$ in $\mathrm{P}$ group, $2.8 \pm 0.6 \mathrm{~cm}$ and $1.5 \pm 0.5 \mathrm{~cm}$,

Table 2 Comparison of intraoperative opioid consumption

\begin{tabular}{|l|l|l|l|}
\hline \multirow{2}{*}{ Intraoperative } & \multicolumn{2}{|l|}{ Groups } & \multirow{2}{*}{ P-value } \\
\cline { 2 - 3 } & $\mathbf{P}(\mathbf{n}=\mathbf{2 5})$ & $\mathbf{C}(\mathbf{n}=\mathbf{2 5})$ & \\
\hline Fentanyl (mcg) & $125(25)$ & $250(75)$ & $<0.00 \mathrm{I}$ \\
\hline
\end{tabular}

Note: Value is expressed as median (IQR), Mann Whitney $U$ test.

Abbreviations: $C$, control group; mcg, microgram; $n$, number of subjects; $P$, Pecs group.

Table 3 Comparison of postoperative pain score

\begin{tabular}{|l|l|l|l|}
\hline \multirow{2}{*}{$\begin{array}{l}\text { Visual analog scale } \\
\text { scores (cm) }\end{array}$} & \multirow{2}{*}{ P-value } \\
\cline { 2 - 3 } & $\begin{array}{l}\text { Groups } \\
(\mathbf{n = 2 5 )}\end{array}$ & & \\
\hline 3 hrs postoperative & $0.7 \pm 0.6$ & $2.8 \pm 0.6$ & $<0.00 \mathrm{I}$ \\
6 hrs postoperative & $1.0 \pm 0.6$ & $2.7 \pm 0.7$ & $<0.001$ \\
12 hrs postoperative & $1.5 \pm 0.5$ & $1.9 \pm 0.7$ & $<0.001$ \\
24 hrs postoperative & $1.3 \pm 0.5$ & $1.9 \pm 0.6$ & $<0.001$ \\
\hline
\end{tabular}

Note: Values are expressed as mean $\pm S D$, independent- $t$ test.

Abbreviations: $\mathrm{C}$, control group; $n$, number of subjects; $\mathrm{P}$, Pecs group. 


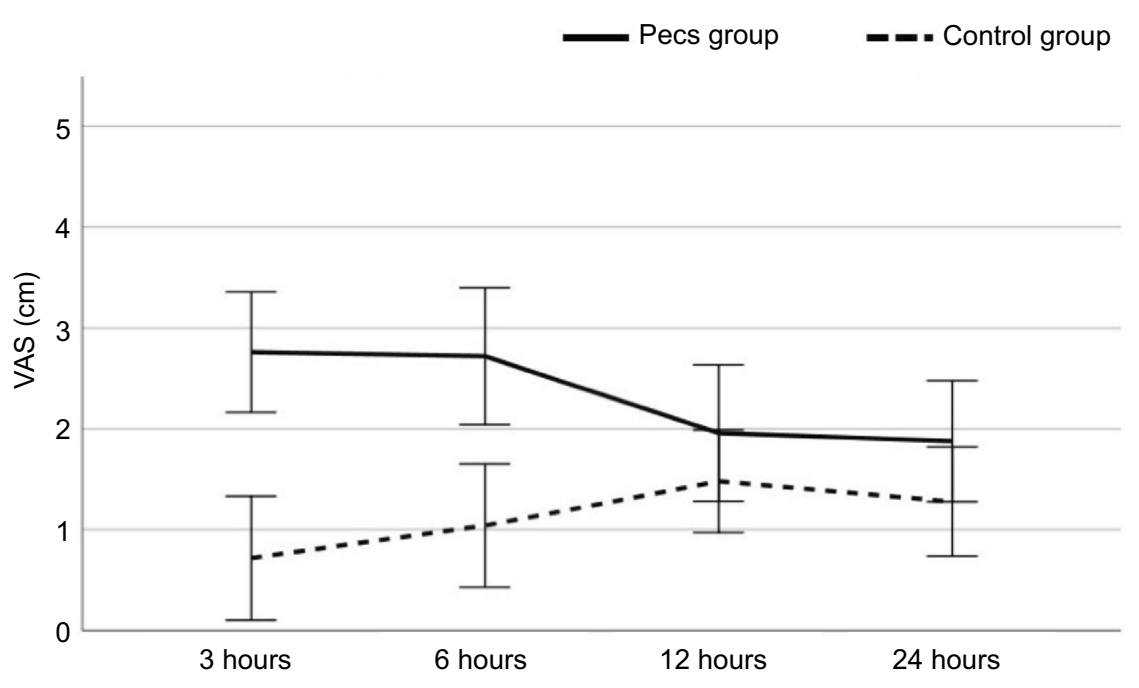

Figure I Visual analog scale scores (VAS) during the first 24 hrs after surgery.

Table 4 Comparison of postoperative opioid consumption

\begin{tabular}{|l|l|l|l|}
\hline \multirow{2}{*}{$\begin{array}{l}\text { Total cumulative dose } \\
\text { of } \text { morphine }(\mathbf{m g})\end{array}$} & \multicolumn{2}{|l|}{ Groups } & \multirow{2}{*}{-value } \\
\cline { 2 - 3 } & $\mathbf{P}(\mathbf{n}=\mathbf{2 5})$ & $\mathbf{C ~ ( n = 2 5 )}$ & \\
\hline 24 hrs postoperative & $3(2)$ & II (4) & $<0.00 \mathrm{I}$ \\
\hline
\end{tabular}

Note: Value is expressed as median (IQR), Mann-Whitney $\mathrm{U}$ test.

Abbreviations: $\mathrm{C}$, control group; $\mathrm{n}$, number of subjects; $\mathrm{P}$, Pecs group.

respectively. The VAS scores in C group were high at 3 and 6 hrs (mean of 2.8 $\pm 0.6 \mathrm{~cm}$ and $2.7 \pm 0.7 \mathrm{~cm}$, respectively), then decreased at 12 and 24 hrs after surgery (mean of $1.9 \pm 0.7 \mathrm{~cm}$ and $1.9 \pm 0.6 \mathrm{~cm}$, respectively). The VAS scores in P group were low at $3 \mathrm{hrs}$ (mean of $0.7 \pm 0.6 \mathrm{~cm}$ ), then elevated at $6 \mathrm{hrs}$ (mean of $1.0 \pm 0.6 \mathrm{~cm}$ ), and reached a peak at $12 \mathrm{hrs}$ after surgery (mean of $1.5 \pm 0.5 \mathrm{~cm}$ ).
Opioid (morphine) consumption after surgery was significantly lower $(P \leq 0.05)$ in $\mathrm{P}$ group than $\mathrm{C}$ group (Table 4 and Figure 2). At $24 \mathrm{hrs}$ after surgery, the median of morphine consumption in $\mathrm{P}$ group was 3 (2) $\mathrm{mg}$ and 11 (4) $\mathrm{mg}$ in $\mathrm{C}$ group. No complications associated with the PECS II block such as hematoma, pneumothorax, and artery puncture were reported.

\section{Discussion}

Breast cancer is the most frequent cancer and causes the highest number of cancer-related deaths among women globally. In 2018, WHO estimates that $6,27,000$ women died from breast cancer, that is approximately $15 \%$ of all cancer-related deaths among women. ${ }^{16}$ The modified radical mastectomy is

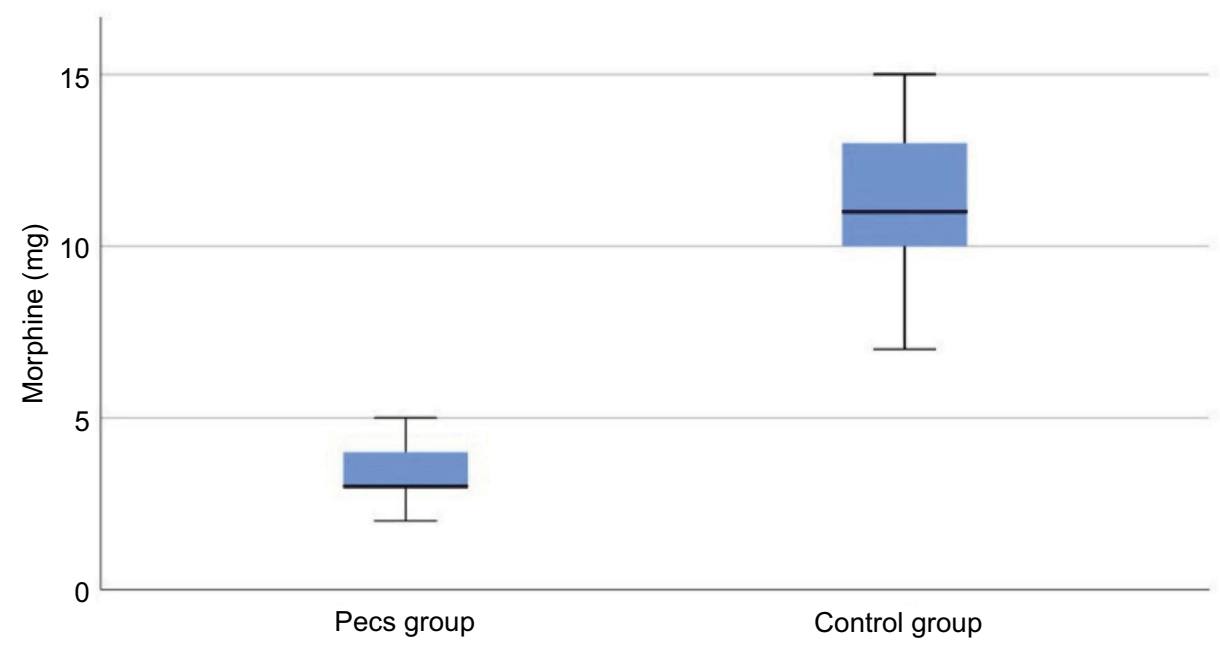

Figure 2 Total morphine requirements 24 hrs after surgery. 
one of the surgical options for breast cancer, which involves removal of the breast and axillary lymph nodes. $^{17}$

Since introduced in 2012 by Blanco et al, Pecs II block gets attention as a new US-guided regional anesthesia for breast surgery. Several $\mathrm{RCT}^{9-14,18}$ and retrospective ${ }^{19,20}$ studies have been published in regard to the effectiveness of Pecs II block. This double-blind and placebo-controlled study shows that opioid requirements intra- and postoperative, and postoperative VAS score were significantly lower in Pecs group than in control (placebo) group. These findings are in accordance with the previous studies.

Pecs II block is applied in the pectoral and axillary regions to anesthetizes the whole breast and axilla. Pecs II block or modified Pecs block involves two injections. The first injection is accomplished by an injection of local anesthetic in the fascial plane between the pectoralis major and minor muscles. This injection is intended to anesthetize the medial $(\mathrm{C} 8, \mathrm{~T} 1)$ and lateral $(\mathrm{C} 5-\mathrm{C} 7)$ pectoral nerves, which innervate the pectoralis muscles. The second injection is lateral to the first injection point in the plane between the pectoralis minor and serratus anterior muscles. This second injection is intended to anesthetize the lateral cutaneous branches of upper intercostal nerves (T2-T6), which will produce the dermatomal anesthesia to the chest wall (pectoral and axillary regions) and the long thoracic nerve (C5-C7), which innervate the serratus anterior muscle. The upper intercostal nerves are ventral rami of thoracic nerves. The intercostal nerves have lateral and anterior cutaneous branches. Each lateral cutaneous branch divides into anterior and posterior terminal branches, except the second intercostal nerve, which is called the intercostobrachial nerve. The anterior terminal branches run forward to the side and the forepart of the chest, supplying the skin and the breast. The posterior terminal branches run backward and supply the skin over the scapula and latissimus dorsi muscle. The intercostobrachial nerve innervates the axilla and medial side of the arm. 3,5,14,15,21

In Pecs II block, the local anesthetics cannot reach the anterior cutaneous branches of the intercostal nerves by piercing the external and internal intercostal muscles. ${ }^{5,14,22}$ Additional block is advised for surgical with an incision in the parasternal area. Blanco et $\mathrm{al}^{5}$ advised to infiltrate between pectoralis major muscle and serratus anterior muscle, but on the medial side, close to the nipple. Ueshima and Kitamura ${ }^{22}$ advised using transverse thoracic muscle plane block, which infiltrate the plane between the transverse thoracic muscle and the internal intercostal muscle between the third and fourth ribs connecting at the sternum.

Postoperative VAS scores were significantly lower in Pecs group than control group at all times of evaluation (3, 6, 12, and 24 hrs after surgery). The VAS scores in control group were high at 3 and $6 \mathrm{hrs}$ after surgery (mean of $2.8 \pm 0.6 \mathrm{~cm}$ and $2.7 \pm 0.7 \mathrm{~cm}$, respectively). In this group, patients did not receive analgesia from the regional technique. In Pecs group, the VAS scores low at $3 \mathrm{hrs}$ (mean of $0.7 \pm 0.6 \mathrm{~cm}$ ), then elevated at $6 \mathrm{hrs}$ (mean of $1.0 \pm 0.6 \mathrm{~cm}$ ), and reached peak at 12 hrs after surgery (mean of $1.5 \pm 0.5 \mathrm{~cm}$ ). The patients in this group received analgesia from Pecs II block. The analgesia of Pecs block lasts for approximately $8 \mathrm{hrs}^{5}$ A regional technique continued into the postoperative period offers postoperative analgesia, attenuation of the surgical stress response, reduction in PONV, and early mobilization. $^{2}$

Postoperatively, patients received multimodal analgesia using IV PCA morphine and IV bolus of ketorolac $30 \mathrm{mg}$ every $8 \mathrm{hrs}$. The underlying principle of multimodal analgesia is that the different modes of action of morphine and the non-opioid drug allow optimum analgesia to be maintained with a lower dose of morphine and consequently a lower incidence of morphine-related adverse effects. ${ }^{23}$ In this study, the median of $24 \mathrm{hrs}$ postoperative morphine consumption was 3 (2) $\mathrm{mg}$ in Pecs group and 11 (4) $\mathrm{mg}$ in control group.

\section{Conclusion}

Combined ultrasound-guided Pecs II block and general anesthesia are effective in reducing pain both intra- and postoperatively in patients undergoing modified radical mastectomy. Ultrasound-guided Pecs II block is a relatively safe peripheral nerve block.

\section{Acknowledgment}

This research received no specific grant from any funding agency in the public, commercial, or not-for-profit sectors.

\section{Disclosure}

The authors report no conflicts of interest in this work. 


\section{References}

1. Turan M, Karaman Y, Karaman S, Uyar M, Gonullu M. Postoperative chronic pain after breast surgery with or without cancer: follow up 6 months. Eur J Anaesthesiol. 2014;31:216. doi:10.1097/00003643201406001-00619

2. Westbrook AJ, Buggy DJ. Anaesthesia for breast surgery. $\mathrm{Br}$ $J$ Anaesth. 2003;8(5):151-154.

3. Gonzales J. PECS versus PVBS for perioperative analgesic management in breast surgery. ASRA News. 2016;16(3):41-44.

4. Blanco R. The 'pecs block': a novel technique for providing analgesia after breast surgery. Anaesthesia. 2011;66(9):847-848. doi:10.1111/ j.1365-2044.2011.06838.x

5. Blanco R, Fajardo M, Maldonado TP. Ultrasound description of Pecs II (modified Pecs I): a novel approach to breast surgery. Rev Esp Anestesiol Reanim. 2012;59(9):470-475. doi:10.1016/j.redar.2012.07.003

6. Ueshima H, Otake H. Ultrasound-guided pectoral nerves (PECS) block: complications observed in 498 consecutive cases. J Clin Anesth. 2017;42:46. doi:10.1016/j.jclinane.2017.08.006

7. Versyck B, Houwe P, Geffen GJ, Velde M, Slappendel R. A qualitative systematic review of the pectoral nerves block type I and II. Acta Anaesthesiol Belg. 2017;68(2):49-62.

8. Nair AS, Sahoo RK, Ganapathy M, Mudunuri R. Ultrasound guided blocks for surgeries/procedures involving chest wall (Pecs 1,2 and serratus plane block). Anaesth Crit Care Pain Med. 2015;19 (3):348-351.

9. Wahba SS, Kamal SM. Thoracic paravertebral block versus pectoral nerve block for analgesia after breast surgery. Egypt J Anaesth. 2014;30(2):129-135. doi:10.1016/j.egja.2013.10.006

10. Kulhari S, Bharti N, Bala I, Arora S, Singh G. Efficacy of pectoral nerve block versus thoracic paravertebral block for postoperative analgesia after radical mastectomy: a randomized controlled trial. Br J Anaesth. 2016;117(3):382-386. doi:10.1093/bja/aew223

11. ELdeen HM. Ultrasound guided pectoral nerve blockade versus thoracic spinal blockade for conservative breast surgery in cancer breast: a randomized controlled trial. Egypt J Anaesth. 2016;32(1):29-35. doi:10.1016/j.egja.2015.08.005

12. Bashandy GM, Abbas DN. Pectoral nerves I and II blocks in multimodal analgesia for breast cancer surgery: a randomized clinical trial. Reg Anesth Pain Med. 2015;40(1):68-74. doi:10.1097/AAP.0000000000000163
13. El-Sheikh SM, Fouad A, Bashandy GN, Al-Azzb MA, Gamal RM. The role of modified PECs block in control of perioperative pain in breast surgeries. Med $J$ Cairo Univ. 2017;85(3):961-966.

14. Kim D, Kim S, Kim CS, et al. Efficacy of pectoral nerve block type II for breast-conserving surgery and sentinel lymph node biopsy: a prospective randomized controlled study. Pain Res Manag. 2018;2018:1-8

15. Blanco R, Barrington MJ. Pectoralis and serratus plane blocks. In: Hadzic A, editor. Hadzic's Textbook of Regional Anesthesia and Acute Pain Management. 2nd ed. New York: McGraw-Hill Education; 2017:650-660.

16. Breast cancer. World Health Organization. Available from: https:// www.who.int/cancer/prevention/diagnosis-screening/breast-cancer /en. Accessed August 5, 2018.

17. Chassin JL. Operative Strategy in General Surgery. New York: Springer; 1984.

18. Kumar S, Goel D, Sharma SK, et al. A randomised controlled study of the post-operative analgesic efficacy of ultrasound-guided pectoral nerve block in the first $24 \mathrm{~h}$ after modified radical mastectomy. Indian $J$ Anaesth. 2018;62(6):436-442.

19. Morioka H, Kamiya Y, Yoshida T, Baba H. Pectoral nerve block combined with general anesthesia for breast cancer surgery: a retrospective comparison. JA Clin Rep. 2015;1. doi:10.1186/ s40981-015-0018-1

20. Yuki I, Ueshima H, Otake H, Kitamura A. PECS block provides effective postoperative pain management for breast cancer surgery - a retrospective study. Int J Clin Med. 2017;8(3):198-203. doi:10.4236/ijcm.2017.83019

21. Collin T, Cox J. Chest wall and breast. In: Standring S, editor. Gray's Anatomy - The Anatomical Basis of Clinical Practice. 41st ed. Oxford: Elsevier; 2016:931-952.

22. Ueshima H, Kitamura A. Blocking of multiple anterior branches of intercostal nerves (Th2-6) using a transversus thoracic muscle plane block. Reg Anesth Pain Med. 2015;40(4):388. doi:10.1097/ AAP.0000000000000245

23. Maund E, McDaid C, Rice S, Wright K, Jenkins B, Woolacott N. Paracetamol and selective and non-selective non-steroidal anti-inflammatory drugs for the reduction in morphine-related side-effects after major surgery: a systematic review. Br J Anaesth. 2011;106(3):292-297. doi:10.1093/bja/aeq406

\section{Publish your work in this journal}

The Journal of Pain Research is an international, peer reviewed, open access, online journal that welcomes laboratory and clinical findings in the fields of pain research and the prevention and management of pain. Original research, reviews, symposium reports, hypothesis formation and commentaries are all considered for publication. The manuscript management system is completely online and includes a very quick and fair peer-review system, which is all easy to use. Visit http:// www.dovepress.com/testimonials.php to read real quotes from published authors. 